\title{
Test anxiety and implicit memory
}

\author{
J. H. MUELLER, M. J. ELSER, and D. N. ROLLACK \\ University of Calgary, Calgary, Alberta, Canada
}

\begin{abstract}
Subjects classified as high or low test-anxious received a standard free recall test as a direct test (explicit memory) following a stem-completion indirect test (implicit memory). As usual, anxious subjects recalled less on the direct test, but were equivalent to low-anxiety subjects on the indirect test. This seemed to be general across anxious-nonanxious words and positive-negative words. The results are consistent with a blockage view of the test anxiety deficit, whereby anxious subjects know things they may not recall on a direct test.
\end{abstract}

The effect of arousal on performance has been of interest to psychologists and educators for many years (see, e.g., Eysenck, 1982; Mueller, 1992). One of the most general observations is that the relation between arousal level and performance can be expressed in terms of an inverted- $U$ function, with optimal performance occurring at intermediate levels of arousal and worse performance at either very high or very low arousal. Arousal can be conceptualized in a variety of ways-as a chronic condition (trait) or as something that is situationally driven (state), as having a well-defined origin (e.g., math anxiety), or as being general and unfocused. In the case of test anxiety, the consensus (see, e.g., Morris, Davis, \& Hutchings, 1981) has emerged that it comprises two components-heightened emotionality, and task-irrelevant cognitive activity or "worry." Instruments such as the Test Anxiety Inventory (Spielberger, 1980) have been developed to assess these two components, and thus to establish the nature of their separate connections with the performance deficit. In general, when a test-anxious person performs poorly, the presumption is that it is the irrelevant thoughts that either compete with task-relevant behavior or use up limited processing resources, whereas emotionality per se has less negative impact. This characterization seems consistent with the evidence, especially when performance is measured in terms of global indices such as semester grade or grade point average (see, e.g., Hembree, 1988).

A portion of the high-anxiety performance deficit may be attributable to activities during the test-specifically, to self-critical or other misdirected thoughts that interfere with task-relevant activity (see, e.g., Sarason, Sarason, \& Pierce, 1990). However, in addition to this "output" problem, the presence of anxiety during study may bias the type of information that is encoded or stored. For one thing, it seems that arousal during study often encourages the learner to attend to superficial features of the experience at the expense of deeper features, and that it tends to produce more restricted rehearsal strategies (see, e.g., Mueller \& Courtois, 1980).

Correspondence can be sent to J. H. Mueller, Educational Psychology Department, University of Calgary, Calgary, AB, Canada T2N1N4 (e-mail: mueller@acs.ucalgary.ca).
A common complaint by students is that "I knew the material, but tensed up and couldn't remember it during the exam"-which is sometimes referred to as the "blockage hypothesis" (see, e.g., Covington \& Omelich, 1987). This may sometimes be a face-saving alibi (a relabeling as "test anxiety" of what is truly a problem in "study anxiety"), but it surely is a veridical self-report in many cases. In fact, we have all experienced momentary retrieval failures possibly even unrelated to test anxiety, lending credibility to the general idea that we often do know things that we are at least temporarily unable to explicitly remember or perform. Contemporary work in cognitive psychology often identifies this as context- or cue-dependent retrieval, on the presumption that restoring the original context will facilitate retrieval (e.g., Baddeley, 1982; Tulving, 1983).

A number of strategies have been employed for dealing with subjects' test anxiety, including relaxation training, training in avoiding self-critical or other irrelevant thinking, coaching in various examination skills designed to enhance test-wiseness, and general training in study habits or skills. When the problem persists, other techniques can be used to accommodate the problem, such as allowing the anxious student to retake exams without penalty, but these often present logistical or other practical problems and possibly raise concerns about pedagogical equity.

The research strategy to be employed here is to compare different types of tests, on the hypothesis that information that is not apparent during one test format will manifest itself on another. Historically, such a strategy might have involved comparing a recall (e.g., essay) test format to a recognition test (e.g., multiple choice), on the argument that the recognition test is easier (or minimizes retrieval), and that test-anxious subjects might thus be less threatened and might do as well as low-anxiety subjects. This generally has not worked very well, because the recognition test format still requires explicit performance (i.e., it is still obviously a "test"). Instead, our strategy is to use indirect tests instead of direct tests, whereby it may be possible to validate the presence of knowledge that is temporarily inaccessible because of the activation of evaluative anxiety when the test involves a direct probe.

This strategy draws on the distinction that has been made between implicit and explicit memory (see, e.g., Lewan- 
dowsky, Dunn, \& Kirsner, 1989; Roediger, 1990). The concept of implicit memory draws on the idea that many activities are performed automatically, without the deliberate calling of specific algorithms to mind. In fact, we are often unable to describe in much detail how we do such things, and furthermore, for many highly skilled activities, it actually seems that conscious attention to one's behavior can degrade performance. Insofar as these phenomena indicate learning that defies deliberate remembrance, some less direct task must be used, one that disguises or even discourages explicit recall. In the laboratory, a direct test might consist of free recall, whereby after studying a set of words (e.g., capable, harm, etc.) subjects are simply required to write them down in any order they choose. However, an indirect test might involve fragment completion following study, presented as a word game or some incidental task, so that for the three-letter stem cap-, implicit memory would be shown when subjects produced a word in the list (capable, as opposed to captain, etc.).

Indirect tasks require subjects to utilize knowledge without their directly being asked for it, and thus information is shown to be available even when it appears to be missing by conventional means. It is not that the indirect tests are just easier in the conventional sense, but that they provide the retrieval cue in a different and more effective manner. Studies have shown that although brain-damaged subjects differ from normals on traditional direct memory tests, there is often little difference between them on tests of implicit memory (e.g., Warrington \& Weiskrantz, 1970). Lorsbach and Worman (1990) have obtained results that suggest a similar outcome for learning-disabled students. Analogous results have been obtained for normal subjects as well, where the effect is generally termed "dissociation," to indicate different results for implicit and explicit tests.

The critical question for us is whether indirect tests will show that test-anxious subjects actually do know things that they are unable to retrieve on a formal, direct test. The research to date is limited and inconclusive. Mathews, Mogg, May, and Eysenck (1989) compared cued recall (explicit memory) and word completion performance (implicit memory) in clinically anxious subjects and normal subjects, using both threatening and nonthreatening words. Their purpose was to establish threat monitoring differences in these groups. Considering just the neutral content in their study, currently anxious subjects seemed to do somewhat worse on both explicit and implicit tests. For the threatening material, currently anxious and normal subjects did not differ on the direct test, but the anxious subjects were clearly better than normals on the indirect test. Richards and French (1991) replicated the finding of a dissociation between implicit and explicit memory tests, but the pattern by anxiety level was not quite the same as that found by Mathews et al. (1989). Thus, in neither case was the pattern precisely the ideal result that would be required for one to conclude that an indirect test effectively revealed material blocked by a direct query. Such a pattern would require that high-anxiety subjects do worse than normals on the direct test, and then do as well on the indirect test.
It could be that results depart from this ideal because of complexities associated with the use of clinically anxious subjects, or the mixture of neutral and threatening material in the study sets may be a problem.

In the present experiment, we explored direct as opposed to indirect tests as a way of better understanding the problems faced by the test-anxious student. Subjects studied a set of words while performing some orienting task that prevented a test expectancy; then the subjects were given an indirect stem-completion test followed by a direct free recall test. We incorporated as an added dimension of the to-be-remembered materials anxiety-relatedness, with half the words related to the anxiety state and half unrelated. Whereas previous research on test anxiety had assessed its effects on explicit memory only in direct tests, we sought to determine whether such effects would also be present for implicit memory as well. Although the test anxiety deficit is well established for explicit memory, whether it would also occur for indirect tests was a matter yet to be determined. If the outcome here should follow that with amnesiacs, we would find that explicit memory differences between high- and low-anxiety subjects would be reduced on an indirect test, which would implicate an output basis for the test-anxiety deficit (e.g., taskirrelevant behavior and other blocking mechanisms). The prospect that the anxiety deficit might be partially due to a study-test context mismatch (see, e.g., Mueller, Lenhart, \& Gustavson, 1989) is broadly compatible with the notion of transfer-appropriate processing that seems implicated in many experiments on indirect tests (cf. Roediger, 1990). That is, the implicit test format might be a very effective way of assuring the matching of study and test context, which might be more of a problem for anxious than for low-anxiety students.

Of course, there is evidence to indicate that anxious subjects also do encode different features than is the case for low-anxiety subjects. Therefore, if the test anxiety deficit should continue to show up on an indirect test as well, this could implicate some type of storage difference for anxious subjects. If so, an implicit test would simply show a smaller test-anxiety deficit than would an explicit test, with the residual difference remaining on the implicit test being due to actual storage differences under high and low anxiety.

\section{METHOD}

\section{Subjects}

The subjects were 116 college students ( 39 male, 61 female; balance unclassified), recruited from undergraduate university courses, and paid $\$ 5$ for the session.

\begin{abstract}
Materials
The experimental items were 48 terms divided into four categories of 12 each: anxious-negative, or high-anxiety exemplars (e.g., anxious, irritable, nervous, tense); anxious-positive, or low-anxiety exemplars (e.g., calm, confident, relaxed, secure); nonanxious-negative (e.g., crude, dishonest, hostile, ungrateful); and nonanxious-positive (e.g., friendly, fair, sincere, polite).
\end{abstract}

\footnotetext{
Procedure

The 48 items were presented in random order for study, with subjects making an impersonal orienting decision for each one ("Are most
} 
Table 1

Average Recall by Item Category for High and Low Test-Anxious Subjects on Direct (Explicit) and Indirect (Implicit) Memory Tests

\begin{tabular}{|c|c|c|c|c|}
\hline \multirow[b]{3}{*}{ Item Content } & \multicolumn{4}{|c|}{ Test } \\
\hline & \multicolumn{2}{|c|}{ Explicit } & \multicolumn{2}{|c|}{ Implicit } \\
\hline & High & Low & High & Low \\
\hline Anxious-positive & 1.83 & 2.27 & 5.06 & 5.36 \\
\hline Anxious-negative & 1.56 & 2.40 & 5.10 & 5.18 \\
\hline Nonanxious-positive & 1.65 & 2.29 & 4.65 & 4.95 \\
\hline Nonanxious-negative & 1.81 & 2.13 & 4.62 & 5.31 \\
\hline Total recall & 6.85 & 9.09 & 19.43 & 20.80 \\
\hline
\end{tabular}

people____ "? yes or no). This was followed by two mental arithmetic problems and an unannounced implicit memory test, on which the first three letters of each word were shown and subjects were required to complete the item.

Two more mental arithmetic problems were presented, and then an unannounced free recall test, with subjects required to write down as many items as possible in any order. This was the explicit memory test.

The experiment concluded with the administration of the Test Anxiety Inventory (TAI; Spielberger, 1980) and the Self-Consciousness Questionnaire (Buss, 1980).

\section{RESULTS AND DISCUSSION}

For purposes of analysis, subjects were divided into high and low anxiety categories on the basis of TAI scores, using a median split $(M d=45)$. The average number of items successfully completed on the indirect completion test and the average number recalled on the direct free recall test are shown in Table 1 , by item type and anxiety level.

The first analysis was of the (direct test) explicit recall data, in a $2 \times 2 \times 2$ analysis of variance for anxiety level (high, low), item content (anxious, nonanxious), and item desirability (positive, negative). There was a significant main effect of anxiety $[F(1,102)=4.71, p<.04]$, with anxious subjects recalling fewer words $(M \mathrm{~s}=6.85$ and 9.09). No other effects or interactions reached significance, including the triple interaction of anxiety $\times$ item content $\times$ item desirability $[F(1,102)=2.14, p<.15]$.

The second analysis was of the (indirect test) implicit completion data (which actually preceded the direct test here), in a similar analysis of variance design. In this case, the high-low anxiety difference was not significant $[M \mathrm{~s}=$ 19.43 and $20.80, F(1,102)<1]$. The main effect of item content was marginally significant $[F(1,102)=3.16, p<$ $.08]$; anxious items were recalled somewhat better than nonanxious items $(M s=20.71$ and 19.55).

In sum, these results are broadly consistent with the idea that the performance of high-anxiety subjects can be enhanced with an indirect test to the point at which their performance is not statistically different from that of lowanxiety subjects. This is roughly in accord with the research on amnesiacs (e.g., Warrington \& Weiskrantz, 1970). In the case of test-anxiety subjects, it can be argued that an indirect test does not evoke the task-irrelevant processing that is said to handicap test-anxious students. As a result, the indirect test allows subjects to display information that would otherwise be blocked on a direct test. Although this is an intriguing result, it bears replication in a betweensubjects format and with additional forms of indirect tests.

\section{REFERENCES}

Baddeley, A. D. (1982). Domains of recollection. Psychological Review, 89, 708-729.

Buss, A. H. (1980). Self consciousness and social anxiety. San Francisco: W. H. Freeman.

Covington, M., \& OMelich, C. L. (1987). "I knew it cold before the exam": A test of the anxiety-blockage hypothesis. Journal of Educational Psychology, 79, 393-400.

EYSENCK, M. W. (1982). Attention and arousal: Cognition and performance. New York: Springer-Verlag.

Hembree, R. (1988). Correlates, causes, effects, and treatment of test anxiety. Review of Educational Research, 58, 47-77.

LeWANDOWSKy, S., DUNN, J. C., \& KIRSNER, K. (1989). Implicit memory: Theoretical issues. Hillsdale, NJ: Erlbaum.

LORSBACH, T. C., \& Worman, L. J. (1990). Episodic priming in children with learning disabilities. Contemporary Educational Psychology, 15, 93-102.

Mathews, A., Mogg, K., May, J., \& Eysenck, M. W. (1989). Implicit and explicit memory bias in anxiety. Journal of Abnormal Psychology, 98, 236-240.

Morris, L. W., Davis, M. A., \& Hutchings, C. H. (1981). Cognitive and emotional components of anxiety: Literature review and a revised worry-emotionality scale. Journal of Educational Psychology, 73, 541-555.

Mueller, J. H. (1992). Anxiety and performance. In A. P. Smith \& D. M. Jones (Eds.), Factors affecting human performance (Vol. 3, pp. 127-160). London: Academic Press.

Mueller, J. H., \& Courtors, M. R. (1980). Test anxiety and breadth of encoding experiences in free recall. Journal of Research in Personality, 14, 458-466.

Mueller, J. H., Lenhart, K., \& Gustavson, K. (1989). Study habits and contextual dependency as a function of test anxiety level. In R. Schwarzer, H. M. van der Ploeg, \& C. D. Spielberger (Eds.), Advances in test anxiety research (Vol. 6, pp. 77-85). Lisse, The Netherlands: Swets \& Zeitlinger.

RichARDS, A., \& FRENCH, C. C. (1991). Effects of encoding and anxiety on implicit and explicit memory performance. Personality \& Individual Differences, 12, 131-139.

RoEDIGER, H. L., III (1990). Implicit memory: Retention without remembering. American Psychologist, 45, 1043-1056.

Sarason, I. G., Sarason, B. R., \& Pịerce, G. R. (1990). Anxiety, cognitive interference, and performance. Journal of Social Behavior \& Personality, 5, 1-18.

SPIELBERGER, C. D. (1980). Preliminary professional manual for the Test Anxiety Inventory. Palo Alto, CA: Consulting Psychologists Press.

Tulving, E. (1983). Elements of episodic memory. New York: Oxford University Press.

WarRington, E. K., \& WeIskrantz, L. (1970). Amnesic syndrome: Consolidation or retrieval? Nature, 228, 628-630.

(Manuscript received June 5, 1993.) 